antiserum (dilutions of $\leq 1$ in 50 ) were used. Even when antiserum was diluted 1 in 50, however, stained virions were clearly discernible over background staining. Staining was equally intense and background manageable with both serum and tissue culture supernatants. Our technique successfully detected virus in samples with infectivity titres of $\mathbf{3 0 0}$ $\mathrm{pfu} / \mathrm{ml}$ or more.

\section{Discussion}

Although filoviruses are morphologically distinct, they may be difficult to detect in fluid preparations poorly preserved or improperly contrast stained. Use of colloidal gold markers assisted in identifying virions in crude specimens. Sensitivity of our procedure is sufficient for most samples, certainly tissue culture fluids, and most acute phase sera. Immunoelectron microscopy sensitivity is similar to that of the antigen capture enzyme linked immunosorbent assay (ELISA). ${ }^{2}$ Tissue culture is more sensitive, but requires more time (three to 10 days). A major advantage of the immunoelectron microscopy fluid technique is that it gives a specific immunological identification of filoviral particles in less than three hours. It therefore has the potential to become a valuable tool for the rapid diagnosis of filoviral infections.

1 Geisbert TW, Jahrling PB. Use of immunoelectron microscopy to show Ebola virus during the 1989 United States scopy to show Ebola virus during the 1989

2 Jahrling PB, Geisbert TW, Dalgard DW, et al. Preliminary report: isolation of Ebola virus from monkeys imported to USA. Lancet 1990;335:502-5.

$3 \mathrm{Lin}$ N. Gold-IgG complexes improve the detection and identification of viruses in leaf dip preparations. $J$ Virol Methods 1984;8:181-90.

4 Hopley JFA, Doane FW. Development of a sensitive protein A-gold immunoelectron microscopy method for detecting viral antigens in fluid specimens. J Virol Methods 1985; 12:135-47.

\title{
Exaggerated and prolonged thyrotrophin releasing hormone (TRH) test responses in tertiary hypothyroidism
}

\author{
G H Mills, R D Ellis, P R Beck
}

Department of

Medicine,

Rotherham District

General Hospital,

Rotherham S60 2UD

G H Mills

Department of Clinical Biochemistry R D Ellis

P R Beck

Correspondence to:

Dr G H Mills

Accepted for publication 6 December 1990

\begin{abstract}
A 60 year old man with panhypopituitarism due to a large meningioma and prolonged and exaggerated thyroid stimulating hormone (TSH) responses is described. Initial investigations showed a subnormal urinary free cortisol concentration, a low serum cortisol taken at 0900 hours, and a low free T4 concentration. The TSH was towards the upper end of the normal range. Subsequently pituitary function tests showed subnormal production of luteinising hormone in response to luteinising hormone releasing hormone (LHRH) and a short synacthen test with a low 30 minute cortisol value. Long synacthen testing showed a normal response at four days, confirming that the abnormalities were due to a pituitary or hypothalamic cause. A computed tomogram showed a large meningioma compressing the hypothalamus, pituitary, and temporal lobe. TRH testing showed a prolonged and exaggerated response, consistent with tertiary hypothyroidism.
\end{abstract}

\section{Case report}

A 60 year old man presented with an 18 month history of episodes of feeling faint. $\mathrm{He}$ also complained of weight gain. These episodes were preceded by an odd smell and a feeling of dread. Examination showed a fall in blood pressure when moving from a supine to upright position $(140 / 100 \mathrm{~mm} \mathrm{Hg}-110 / 90$ $\mathrm{mm} \mathrm{Hg}$ ). These episodes were not associated with standing up, however. His general practitioner had checked his serum cortisol concentration at 0900 hours and found a low value of $163 \mathrm{nmol} / \mathrm{l}$ (normal range 240-722 $\mathrm{nmol} / \mathrm{l}$ ). In view of the patient's persistent tiredness he had rechecked a previously borderline low thyroid function test. On this occasion the free T4 was $8 \cdot 1 \mathrm{pmol} / 1$ (normal range 8.6-27 pmol/1), and the (TSH) $5.3 \mathrm{mIU} / 1$ (normal range $0.5-6.5 \mathrm{mIU} / \mathrm{l}$ ). Thyroid and adrenal antibodies subsequently proved negative. The patient also admitted loss of facial and body hair over the preceding two years.

Overall, the differential diagnosis was felt to be between hypopituitarism or hypoadrenalism, with possible temporal lobe epilepsy. 
Combined pituitary function test results. (Shaded areas indicate normal response ranges.)

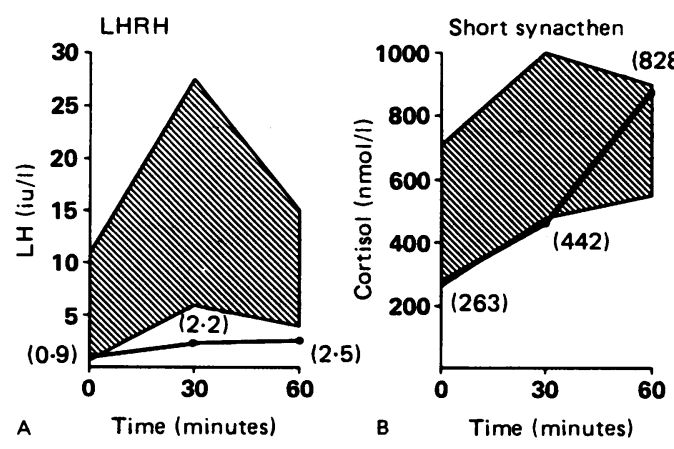

The patient's hypothalamic pituitary adrenal (HPA) axis was investigated, using urinary free cortisol concentration, diurnal plasma cortisol concentration, and combined pituitary function, together with short and long synacthen tests. The combined pituitary function test required $200 \mu \mathrm{g}$ TRH and $100 \mu \mathrm{g} \mathrm{LHRH}$. The short synacthen test required $250 \mu \mathrm{g}$ synacthen. A long synacthen test was also performed with daily injections of $1 \mathrm{mg}$ depot synacthen given intramuscularly for three days.

Basal activities of free T4 were low at 6.3 (normal range 8.6-27 pmol/1). TSH equalled $6.4 \mathrm{mIU} / 1$ (normal range $0 \cdot 5-6 \cdot 8$ ). Testosterone was low at $0 \cdot 8$ (normal range $11 \cdot 7-44 \cdot 4$ $\mathrm{nmol} / \mathrm{l}$ ), and urinary free cortisol was also low at 62 (normal range $97-258 \mathrm{nmol} / 24$ hours). Combined pituitary function tests showed an exaggerated TSH response to TRH (fig 1D) (normal range basal activity $0.5-6.8 \mathrm{mIU} / 1$, increasing by more than $2 \mathrm{mIU} / 1$ above basal at 20 minutes), ${ }^{12}$ prolactin response to TRH was normal (fig 1C), ${ }^{3}$ with an inadequate response to $\mathrm{LHRH},{ }^{4}$ suggesting a pituitary based hypogonadism. Basal cortisol concentrations were normal but 30 minutes after synacthen the response was subnormal at 442 nmol/l, suggesting hypoadrenalism (fig 1B). The normal range includes a basal concentration greater than $650 \mathrm{nmol} / \mathrm{l}$ and an upper limit three times the basal concentrations. ${ }^{5}$ A long synacthen test was performed to investigate the nature of the hypoadrenalism. A normal response (cortisol $917 \mathrm{nmol} / \mathrm{l}$ ) was obtained on the fourth day. This suggested hypopituitarism.

\section{Discussion}

On the basis of these data there is evidence for both primary hypothyroidism and panhypopituitarism. There have been reports, however, of an atypical exaggerated TSH response to TRH testing, especially in patients with hypothalamic hypothyroidism. Our patient was confirmed on computed tomography to have a meningioma arising from the right anterior clinoid process, which compressed the hypothalamus and pituitary and extended into the left temporal lobe. This produced symptoms of temporal lobe
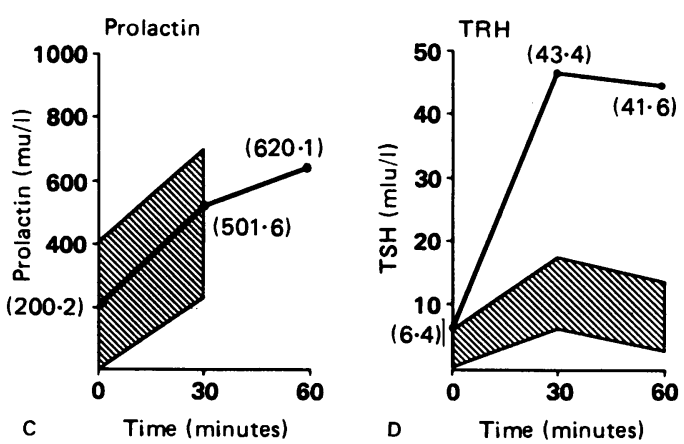

epilepsy. His biochemical results suggest a hypothalamic/pituitary cause for his endocrinological abnormalities, consistent with those described by Faglia et al. ${ }^{6}$ Their patients showed a prolonged and exaggerated response more typical of primary hypothyroidism ${ }^{6}$; in typical tertiary hypothyroidism due to hypothalamic damage there is an initial low $\mathrm{T} 4$, low or normal basal TSH, and a normal or delayed $\mathrm{TSH}$ response. With a secondary hypothyroid response due to pituitary damage there is a low T4, low or normal basal TSH, and an absent TRH response.

In 1973 Faglia et al suggested that delayed, prolonged, and exaggerated responses to TRH testing were characteristic of hypothalamic disorders. ${ }^{7}$ They also saw this response after TRH testing in some patients with pituitary tumours. ${ }^{6}$ It has been shown that in cases of tertiary hypothyroidism additional TSH is largely biologically inactive. ${ }^{89}$

Our patient had a low T4 activity, combined with a relatively high basal TSH and exaggerated TRH response, emphasising that hypothalamic disorders may produce biochemical results which mimic those of primary hypothyroidism.

1 Hall R. In: Hall R, Besser GM, eds. In: Thyroid. Fundamentals of clinical endocrinology. 4th ed. Edinburgh: Churchill Livingstone, 1989:81-2

2 Eastham RD. In: Hall R, Besser GM, eds. In: Thyrotropin response to thyrotropin releasing hormone. Fundamentals response to thyrotropin releasing hormone. Fundamentals
of clinical endocrinology 4th ed. Edinburgh: Churchill of clinical endocrinology 4 .
Livingstone, 1989, 391-3.

3 Eastham RD. In: Prolactin response to TRM. Biochemical values in clinical medicine. 7th ed. Bristol: PG Wright, 1985:393.

4 Ismail AAA. In: Disorders of gonadal function in the male. Biochemical investigations in endocrinology. London Academic Press, 1981:172-4.

5 Drury PL, Besser GM. In: Adrenal vortex. Fundamentals of clinical endocrinology 4th ed. Edinburgh: Churchill Livingstone, 1989:171-2.

6 Faglia G, Beck-Peccoz P, Ambrosi B, Ferrari G, Neri V. Prolonged and exaggerated elevations in plasma thyrotrophin (HTSH) after thyrotrophin releasing factor TRF) in patients with pituitary rumours ractor Endocrinol Metab 1971;33:999-1002.

7 Faglia G, Beck-Peccoz P, Ferrari C, et al. Plasma thyrotropin response to thyrotropin-releasing hormone in patients with pituitary and hypothalamic disorders. J Clin patients with pituitary and hypotha

8 Faglia G, Bitensky L, Pinchera A, et al. Thyrotrophin secretion in patients with central hypothyroidism: evidence for reduced biological activity of immunoreactive thyrotrophin. J Clin Endocrinol Metab 1979;

9 Spitz IM, Leroith DL, Hirsch H, et al. High molecular weight human TSH with impaired biological activity. $N$ Engl J Med 1981;304:278-82. 